\title{
Identification of Comamonas species using 16S rRNA gene sequence
}

\author{
Vimlesh Yadav ${ }^{1}$, Satya Prakash ${ }^{1}$, Shipra Srivastava ${ }^{1}$, Praveen Chandra Verma ${ }^{2,3}$, Vijayta Gupta ${ }^{3}$, Vaishali Basu ${ }^{3}$ and Anil Kumar \\ Rawat $^{1, *}$ \\ ${ }^{1}$ Biotechnology and Bioinformatics Division, BIOBRAINZ, 566/29 J, Jai Prakash Nagar, Alambagh, Lucknow 226005, U.P., India; \\ ${ }^{2}$ Department of Biotechnology, Madhav Institute of Technology \& Science, Gwaliar (MP), ${ }^{3}$ Present address: National Botanical Research \\ Institute, Rana Pratap Marg, Lucknow, U.P. India. Anil Kumar Rawat - E-mail: akrbz@rediffmail.com; Phone No: $91-0522$ 4042284; \\ *Corresponding Author
}

Received March 05, 2009; accepted May 16, 2009; published June 13, 2009

\begin{abstract}
:
A bacterial strain $\mathrm{Bz} 02$ was isolated from a water sample collected from river Gomti at the Indian city of Lucknow. We characterized the strain using 16S rRNA sequence. Phylogenetic analysis showed that the strain formed a monophyletic clade with members of the genus Comamonas. The closest phylogenetic relative was Comamonas testosteroni with 95\% 16S rRNA gene sequence similarity. It is proposed that the identified strain Bz02 be assigned as the type strain of a species of the genus Comamonas (Comamonas sp Bz02) based on 16S rRNA gene sequence search in Ribosomal Database Project, small subunit rRNA and large subunit rRNA databases together with the phylogenetic tree analysis. The sequence is deposted in GenBank with the accession number FJ211417.
\end{abstract}

Keywords: 16S ribosomal RNA gene; Comamonas; PCR; Phylogenetic analysis; DNA isolation; DNA Sequencing

\section{Background:}

The river Gomiti in India represents a unique niche for biodiversity. We initiated a systematic screening programme to catalogue the microbial composition of Gomti river water at the Indian city Lucknow (isolate Bz02). Characterization of bacterial species using classical methods is not as specific as the genotyping methods. Comparison of the bacterial 16S rRNA gene sequence has emerged as a preferred genetic technique [1]. Species specific 16S rRNA gene sequence is present across the bacterial kingdom. Studies related to the strain $\mathrm{Bz} 02$ with potential similarity to Comamonas strains is of interest and relevance to this work (as observed by morphological characterization). It is known that Comamonas strains are involved in bioremediation. The degradation of 4toluenesulfonic acid in a continuously operated fixed-bed biofilm reactor is shown using Comamonas testosteroni [2] and degradation of the anion-active surfactant dihexylsulfosuccinat is shown using Comamonas terrigena strain $\mathrm{N} 3 \mathrm{H}$ [3]. The Comamonas strains JS46 and JS47 have been used in mixed and non-mixed culture immobilized cell reactors for the degradation of $\mathrm{m}$ - and $\mathrm{p}$-nitrobenzoate [4]. Thus, members of this genus have potential application in bioremediation. Therefore, it is of interest to isolate novel bacterial strains from different environments for potential bioprocess application. This involves isolation and characterization using classical microbiology and genetic screening. The genotyping method used in the identification of new strains is simple and effective [1]. In this study, we describe the isolation and identification of an unknown bacterium from the Indian river Gomti using $16 \mathrm{~S}$ rRNA gene sequence to characterize the strain $\mathrm{Bz} 02$ as a member of the Comamonas.

\section{Methodology:}

\section{Culturing of Bacteria}

Water sample collected from the Gomti River was serially diluted and spread onto peptone/Beef extract/Nacl/AgarAgar plates followed by for incubation at $30^{\circ} \mathrm{C}$ under anaerobic conditions. Single colonies of bacterial strains were picked and further grown and sub-cultured several times to obtain a pure culture.

\section{DNA isolation of bacteria}

Pure culture of the target bacteria was grown overnight in liquid NB medium for the isolation of genomic DNA using a method described by Hiney and colleagues [5].

\section{PCR amplification 16S rDNA gene}

PCR reaction was performed in a gradient thermal cycler (Eppendorf, Germany). The universal primers (Forward primer 5'- AGAGTTTGATCCTGGCTCAG -3' and reverse primer 5'- CTTGTGCGGGCCCCCGTCAATTC-3') were used for the amplification of the 16S rDNA gene fragment. The reaction mixture of $50 \mu \mathrm{l}$ consisted of $10 \mathrm{ng}$ of genomic DNA, $2.5 \mathrm{U}$ of Taq DNA polymerase, $5 \mu \mathrm{l}$ of 10 X PCR amplification buffer (100 mM Tris- $\mathrm{HCl},, 500 \mathrm{mM}$ $\mathrm{KCl} \mathrm{pH}-8.3), 200 \mu \mathrm{M}$ dNTP, $10 \mathrm{p}$ moles each of the two universal primers and $1.5 \mathrm{mM} \mathrm{MgCl}_{2}$. Amplification was done by initial denaturation at $94^{\circ} \mathrm{C}$ for 3 minutes, followed by 30 cycles of denaturation at $94^{\circ} \mathrm{C}$ for 30 second, annealing temperature of primers was $55^{\circ} \mathrm{C}$ for 30 second and extension at $72^{\circ} \mathrm{C}$ for 1 minute. The final extension was conducted at $72^{\circ} \mathrm{C}$ for 10 minutes.

\section{Agarose gel electrophoresis}

$10 \mu \mathrm{l}$ of the reaction mixture was then analyzed by submarine gel electrophoresis using $1.0 \%$ agarose with ethidium bromide at $8 \mathrm{~V} / \mathrm{cm}$ and the reaction product was visualized under Gel doc/UV trans-illuminator.

\section{Purification of PCR product}

The PCR product was purified by Qiagen gel extraction kit using the following protocol described below. The DNA fragment was excised from the agarose gel with a clean sharp scalpel. Then the gel slice was weighed in an eppendorf. We then added 3 volumes of buffer QG to 1 volume of gel $(100 \mathrm{mg} \sim 100 \mu \mathrm{l})$. The mixture was then incubated at $50^{\circ} \mathrm{C}$ for 10 minutes. The gel was dissolved by 
vortexing the tube every 2-3 min during the incubation until the mixture color is uniformly yellow. We then added 1 gel volume of Iso-propanol to the sample and mixed. A QIAquick spin column is then placed in a $2 \mathrm{ml}$ collection tube provided. The sample is applied to the QIAquick column followed by centrifugation for one minute so that DNA binds to the column. The flow-through is discarded and the QIAquick column is placed back in the collection tube. We then added $0.75 \mathrm{ml}$ of buffer PE to QIAquick column and centrifuged for 1 minute to wash. The flowthrough is again discarded and the QIAquick column centrifuged for an additional 1 minute at $10,000 \times g$. The QIAquick column is now placed into a clean $1.5 \mathrm{ml}$ eppendorf. We then added $50 \mu 1$ of buffer EB $(10 \mathrm{mM}$ Tris$\mathrm{Cl}, \mathrm{pH} 8.5$ ) to the center of the QIAquick membrane and centrifuged the column for $1 \mathrm{~min}$ to elute DNA.

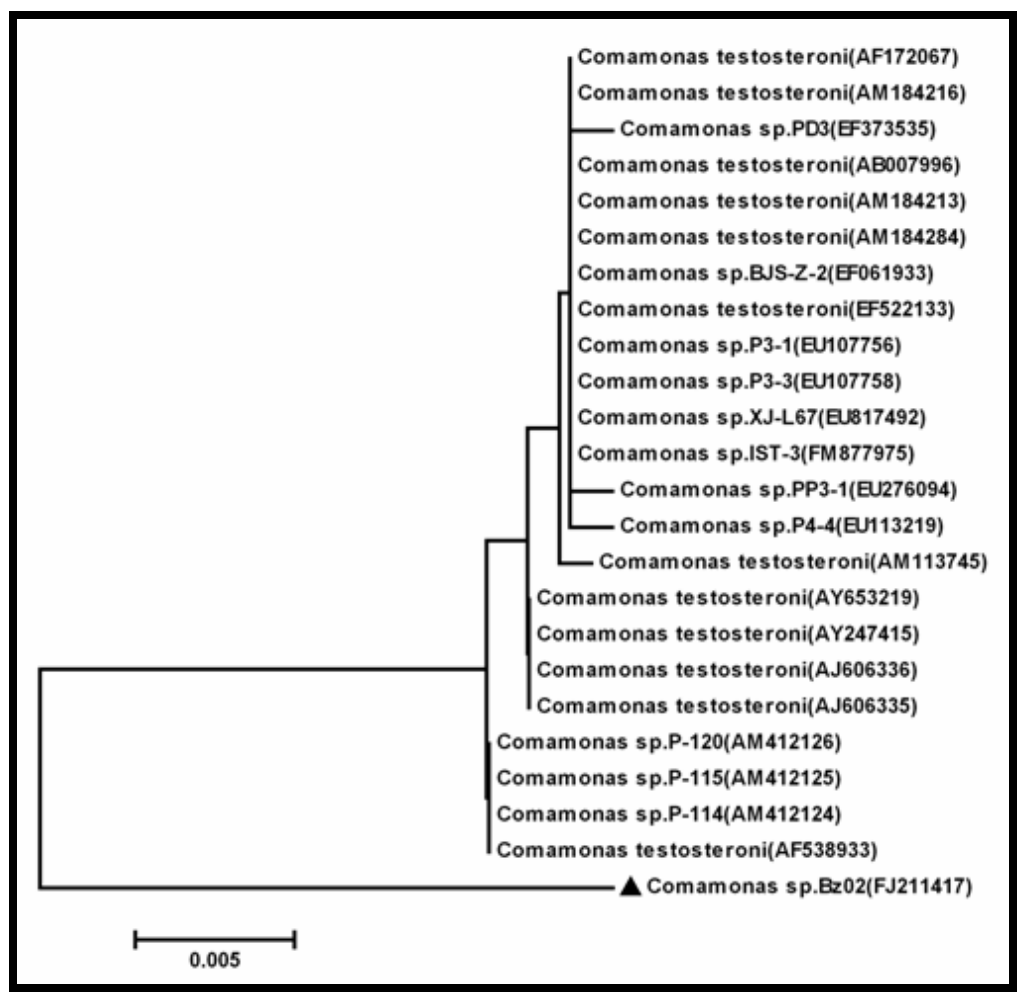

Figure 1: Neighbour-joining tree of selected 16S rRNA gene sequences of the genus Comamonas obtained from BLAST search of the Bz02 strain sequence for phylogenetic inference.

DNA sequencing of the 16S rDNA fragment

The 16S rDNA amplified PCR product (100ng concentration) was used for the sequencing with the single $16 \mathrm{~S}$ rDNA 27F Forward primer: 5'AGAGTTTGATCCTGGCTCAG-3’ by ABI DNA sequencer (Applied Biosystem Inc).

Computational analysis:

Identification of Comamonas sp

A comparison of the 16s rRNA gene sequence of the test strain with the non-redundant collection (Genbank, DDBJ, EMBL \& PDB) of sequences was performed using BLAST $[6,7]$. A number of sequences of the genus comamonas aligned with $16 \mathrm{~S}$ rRNA gene sequence of test strain. We then developed a multiple sequence alignment for these homologous sequences using the algorithm described in ClustalW [8]. Subsequently, an evolutionary distance matrix was then generated from these nucleotide sequences in the dataset. A phylogenetic tree was then drawn using the Neighbour joining method [9]. Phylogenetic and molecular evolutionary analyses were conducted using MEGA (Molecular Evolutionary Genetics analysis) version 4.0 [10]. We compared the $16 \mathrm{~S}$ rRNA gene sequence of test strain with different set of sequence databases such as small subunit ribosomal RNA (ssu rRNA) and large subunit ribosomal RNA (lsu rRNA) [11] by using Ribosomal RNA BLAST [12]. 16S rRNA gene sequence of test strain is also compared against those sequences in Ribosomal Database Project (RDP) [13] by using the RDP Classifier check Program [14]. The annotated information for the sequence in the database to which 16S rRNA aligns is used for the bacterial identification.

\section{Discussion:}

The rRNA based analysis is a central method in microbiology used not only to explore microbial diversity but also to identify new strains. The genomic DNA was extracted from isolated bacterial strain $\mathrm{Bz} 02$ and universal primers $27 \mathrm{~F}$ and $939 \mathrm{R}$ were used for the amplification and sequencing of the $16 \mathrm{~S}$ rRNA gene fragment. A total of 758 $\mathrm{bp}$ of the 16S rRNA gene was sequenced and used for the identification of isolated bacterial strain. Subsequently, a 16S rRNA gene sequence based phylogenetic tree showing the relationships between the test strain $\mathrm{Bz} 02$ and selected representatives of the genus Comamonas is given in figure 1. It is evident from phylogenetic analysis of 16S rRNA gene that the isolate $\mathrm{Bz} 02$ represents a genomic species in 


\begin{abstract}
the genus Comamonas. Comparison of test strain against known sequences of ssu rRNA and lsu rRNA databases showed that the gene sequence of isolate $\mathrm{Bz} 02$ has $95 \%$ sequence similarity (Score $=1199$ bits, Expect $=0.0$ ) with 16S rRNA gene sequence of Comamonas testosteroni (Genbank Acc. No.: M11224). Thus, data shows that the isolate $\mathrm{Bz} 02$ is a member of the genus Comamonas. Similarity rank program classifier [14] available at the Ribosomal Database Project [13] classified the isolate $\mathrm{Bz02}$ as a novel genomic species of the genus Comamonas with a confidence threshold of $95 \%$.
\end{abstract}

\section{Conclusion:}

Bacterial species have at least one copy of the 16S rRNA gene containing highly conserved regions together with hyper variable regions. The use of $16 \mathrm{~S}$ rRNA gene sequences to identify new strains bacteria is gaining momentum in recent years. We showed the use of $16 \mathrm{~S}$ rRNA gene sequence to characterize the bacterial isolate $\mathrm{Bz} 02$ from Gomti River in the Indian city of Lucknow. Thus, the genotyping method using 16S rRNA gene sequence is both simple and effective in strain characterization.

\section{Acknowledgement:}

The present work was supported by a joint venture of the laboratory facilities at Chromous Biotech Pvt. Ltd. Bangalore, India and Biotechnology and Bioinformatics Division, BIOBRAINZ, Lucknow, U.P., India.

\section{Hypothesis}

References:

[1] E. Jill, \& III. Clarridge, Clinical Microbiology Reviews, 17: 840 (2004) [PMID: 15489351]

[2] A. Khlebnikov \& P. Peringer, Water Science and Technology, 34: 257 (1996)

[3] M. Proksova et al., Folia Microbiol., 42: 635 (1997) [PMID: 9508556]

[4] J.L. Goodall et at.,Biotechnol Bioeng., 59:21 (1998)[PMID: 10099310]

[5] M. Hiney et al., Appl Environ Microbiol., 58: 1039 (1992) [PMID: 1575477]

[6] http://blast.ncbi.nlm.nih.gov/Blast.cgi

[7] Z. Zhang et al., J Comput Biol., 7: 203 (2000) [PMID: 10890397]

[8] J.D. Thompson et al., Nucleic Acids Res., 22: 4673 (1994) [PMID: 7984417]

[9] N. Saitou and M Nei, Mol Biol Evol., 4: 406 (1987) [PMID: 3447015]

[10] K. Tamura et al., Mol Biol Evol., 24: 1596 (2007)[PMID: 17488738]

[11] J. Wuyts et al., Nucleic Acids Res., 32: D101 (2004) [PMID: 14681368]

[12] http://bioinformatics.psb.ugent.be/webtools/rRNA/ blastrrna.html

[13] http://rdp.cme.msu.edu/

[14] Q. Wang et al., Appl Environ Microbiol., 73: 5261 (2007) [PMID: 17586664]

Edited by P. Kangueane

Citation: Yadav et al, Bioinformation 3(9): 381-383 (2009)

License statement: This is an open-access article, which permits unrestricted use, distribution, and reproduction in any medium, for non-commercial purposes, provided the original author and source are credited. 